\title{
Influence of annealing temperature on the
}

\section{structural and electrical properties of Si-doped}

\section{ferroelectric hafnium oxide - supplementary}

\section{material}

Maximilian Lederer, ${ }^{*} \dagger$ Pratik Bagul, ${ }^{\dagger}$ David Lehninger, ${ }^{\dagger}$ Konstantin Mertens, ${ }^{\dagger}$ André Reck, ${ }^{\dagger}$ Ricardo Olivo, ${ }^{\dagger}$ Thomas Kämpfe, ${ }^{\dagger}$ Konrad Seidel, ${ }^{\dagger}$ and Lukas M. Eng $\ddagger$

$†$ Fraunhofer IPMS, Center Nanoelectronic Technologies, An der Bartlake 5, 01109 Dresden, Germany

$\ddagger T U$ Dresden, Institute for Applied Physics, 01062 Dresden, Germany, and

Center of Excellence - Complexity and Topology in Quantum Matter (ct.qmat), Technische Universität Dresden, 01062 Dresden, Germany.

E-mail: maximilian.lederer@ipms.fraunhofer.de 


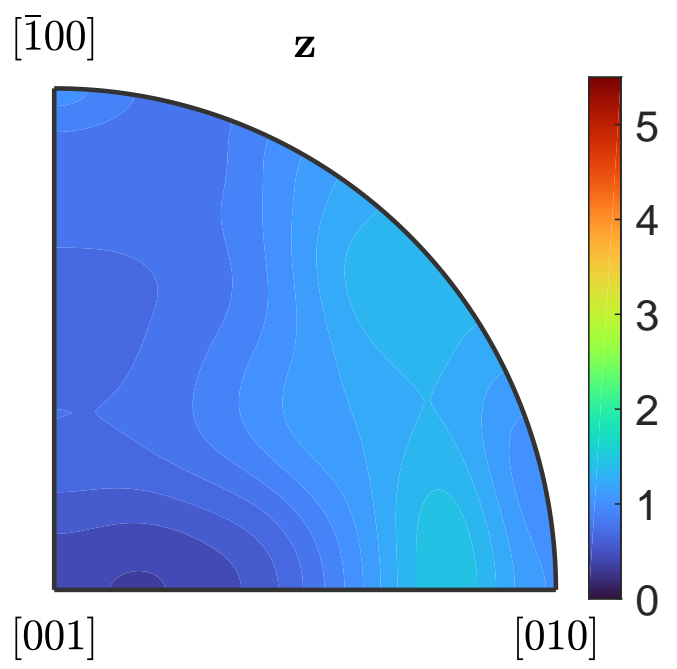

Figure S1: Inverse pole figure (IPF) of an Si-doped $\mathrm{HfO}_{2}$ sample with metal-ferroelectricinsulator-semiconductor stack structure annealed at $800^{\circ} \mathrm{C}$. 